Research Article

\title{
Chemical Constituents, Antioxidant Activities, and Element Concentrations of Rusa Deer Velvet Antler Extracts
}

\author{
Chutima Limmatvapirat ${ }^{\mathbb{D}},{ }^{1}$ Potcharet Rodhetbhai, ${ }^{1}$ Krittaphas Somsakraksanti, ${ }^{1}$ \\ Pitcha Danpongprasert, ${ }^{1}$ Soranun Poonsub, ${ }^{1}$ Wantanwa Krongrawa, ${ }^{2}$ \\ Sontaya Limmatvapirat, ${ }^{2}$ and Maneerat Meepan ${ }^{3}$ \\ ${ }^{1}$ Department of Pharmaceutical Chemistry, Faculty of Pharmacy, Silpakorn University, Nakhon Pathom 73000, Thailand \\ ${ }^{2}$ Department of Pharmaceutical Technology, Faculty of Pharmacy, Silpakorn University, Nakhon Pathom 73000, Thailand \\ ${ }^{3}$ Siam Ostrich Co. Ltd., 361 Soi Inthamara 41, Sutthisarn Road, Din Daeng, Bangkok 10400, Thailand
}

Correspondence should be addressed to Chutima Limmatvapirat; limmatvapirat_c@su.ac.th

Received 1 July 2020; Accepted 21 August 2020; Published 15 October 2020

Academic Editor: Angela Patti

Copyright (c) 2020 Chutima Limmatvapirat et al. This is an open access article distributed under the Creative Commons Attribution License, which permits unrestricted use, distribution, and reproduction in any medium, provided the original work is properly cited.

\begin{abstract}
The objective of this study was to analyze hexane extract (HE), 75\% v/v ethanol extract (EE), and water extract (WE) of rusa deer velvet antlers, obtained through a three-solvent sequential extraction, for determining their chemical constituents, antioxidant activities, element concentrations, and microbial contamination. In TLC, FTIR, ${ }^{1} \mathrm{H}$ NMR, and HPLC analysis, HE and EE showed the presence of oleic acid, linoleic acid, alpha-linolenic acid, and testosterone. EE showed the highest concentration of testosterone and the strongest antioxidant activity in DPPH and FRAP assays. In addition, the concentration of testosterone in EE was higher than in sika deer and red deer velvet antler extracts found in other studies. All extracts were composed of essential elements and had levels of toxic elements and microbial contaminants lower than the acceptable criteria set by ASEAN guidelines. Thus, EE was considered to be a safe and useful source of antioxidants and testosterone.
\end{abstract}

\section{Introduction}

The rusa deer (Cervus rusa timorensis) was imported into Thailand and widely used in commercial farming for the production of velvet antlers [1]. Velvet antlers are precious cranial appendages that grow on top of the frontal protuberances in male deer, belonging to the family Cervidae. They have been used in Asian countries for more than a thousand years with a variety of medicinal purposes including antioxidant, antifatigue, immunomodulating, and libido boosting. Steroid hormones, chondroitin sulphate, phospholipids, $p$-hydroxybenzaldehyde, and protein hydrolysate were thought to be antioxidants found in velvet antler extracts [2]. Testosterone in velvet antlers was effective in improving sexual function and boosting libido [3]. Consequently, the concentration of natural testosterone is used as the criterion for estimating the quality of velvet antler extracts. Because of its therapeutic potential and low toxicity [4], the velvet antler extract could be used as an active ingredient in nutraceuticals and functional foods against various illnesses.

Recently, a sequential multisolvent extraction process has been widely used to extract chemical components from medicinal plants and animals because it reduces the consumption of precious natural raw materials [5]. Furthermore, this extraction process can be easily applied by Small Manufacturing Enterprises (SMEs). This study therefore extracted a sample of velvet antlers sequentially using a multisolvent extraction process of 3 organic solvents in order to increase polarity.

Bioactive compounds in velvet antler extracts may decrease and these extracts can often be contaminated with heavy metals and pathogenic microorganisms during processing and storage; therefore, it is crucial to evaluate quality, safety, and efficacy of these extracts. Until now, there has still been no report pertaining to the chemical constituents and 
antioxidant activities of rusa deer antler velvet extracts prepared by a sequential extraction. Thus, the objectives of this study were to compare several extracts of rusa deer velvet antlers obtained from a three-solvent sequential extraction process for determining their chemical constituents, antioxidant activities, essential and toxic element concentrations, and microbial contamination.

\section{Materials and Methods}

2.1. Chemicals. Potassium bromide, FTIR grade, was purchased from Thermo Fisher Scientific (Massachusetts, USA). Chloroform-d, methanol- $\mathrm{d}_{4}$, dimethyl sulfoxide- $\mathrm{d}_{6}$, testosterone purum with purity greater than $99.0 \%$ (HPLC), 2,2diphenyl-1-picrylhydrazyl (DPPH), 2,4,6-tris(2-pyridyl)-striazine (TPTZ), acetate buffer, and ferric chloride hexahydrate were bought from Sigma-Aldrich Chemical Corporation (St. Louis, MO, USA). For TLC analysis, reference standards with at least $99 \%$ purity including oleic acid, linoleic acid, and alpha-linolenic acid as well as silica gel 60 $\mathrm{F}_{254}$ TLC aluminium sheets were purchased from $\mathrm{Nu}$-Chek Prep, Inc. (Minnesota, USA) and Merck KGaA (Darmstadt, Germany), respectively. L-ascorbic acid was bought from Chem-Supply Pty Ltd. (Gillman, South Australia). ICP multielement standard solution XIII was purchased from Agilent Technologies (Santa Clara, USA). All media were purchased from Sigma-Aldrich Chemical Corporation (Steinheim, Germany) and all other chemicals were of analytical grade and purchased from Sigma-Aldrich Chemical Corporation (St. Louis, MO, USA).

2.2. Velvet Antlers and Extraction. Velvet antlers from rusa deer (C. timorensis) were provided by the Siam Ostrich Farm, an organic farm in Amphoe Song Phi Nong, Suphan Buri Province, Thailand. The deer were fed with $80 \%$ mixture of Napier grass (Pennisetum purpureum) and baby corn (Zea mays L.) stalks and leaves. The antlers were harvested from 3-year-old male deer, 65-70 days after the antlers regenerated from their pedicles. The removal of antlers must be performed under the direct supervision of a licensed veterinarian. The antlers were surface sterilized with $75 \% \mathrm{v} / \mathrm{v}$ ethanol and cut off by a surgical hand saw, and the blood then drained out of the harvested antlers. A voucher specimen was assigned a reference number and deposited in the Department of Pharmaceutical Chemistry, Faculty of Pharmacy, Silpakorn University. The antlers were sliced with a bone slicer, dried in an oven set at $50 \pm 2^{\circ} \mathrm{C}$, powdered into the homogeneous size of 120-140 mesh (Partica LA-950, Horiba, Japan), and extracted by a three-solvent sequential process. Powdered sample $(168.59 \mathrm{~g})$ was sonicated $(2 \mathrm{~h})$ in hexane $(850 \mathrm{~mL})$ at room temperature and then filtered through a Whatman filter paper No. 1 (Merck KGaA, Darmstadt, Germany) using a vacuum filtration. The process was repeated with the residue sonicated $(24 \mathrm{~h})$ in $75 \% v / v$ ethanol $(1,000 \mathrm{~mL})$ at room temperature and lastly digested $(24 \mathrm{~h})$ in ultrapure water $(1,000 \mathrm{~mL})$ at $45^{\circ} \mathrm{C}$. Each extract was filtered and dried using a rotary evaporator (R-100, Buchi, Japan) at $45^{\circ} \mathrm{C}$ under a reduced pressure. Finally, the residual water in each extract was removed using a freeze dryer, Model 6112974 (Labconco, Kansas City, MO, USA). All extracts including hexane, $75 \% v / v$ ethanol, and water extracts (HE, EE, and WE) were kept in the dark at $4{ }^{\circ} \mathrm{C}$ until use.

2.3. Identification of Fatty Acids and Testosterone in Extracts Using Thin Layer Chromatography (TLC). Thin-layer chromatography (TLC) qualification performed by external standard method [6] was modified for simultaneous detection of oleic acid, linoleic acid, and alpha-linolenic acid in velvet antler extracts. Three extracts (HE, EE, and WE) were dissolved in hexane, $75 \% v / v$ ethanol, and ultrapure water, respectively, while fatty acid standards were dissolved individually in chloroform to obtain $1 \mathrm{mg} / \mathrm{mL}$ solutions. Approximately $5 \mu \mathrm{L}$ of each extract and fatty acid solution was spotted on a silica gel $60 \mathrm{~F}_{254}$ plate $(250 \mu \mathrm{m}$ thickness $)$ using hexane: ethyl acetate: acetic acid (60: 40: 0.5, $v / v / v)$ as a developing organic solvent to a distance of $10 \mathrm{~cm}$. TLC patterns of extracts and standards were confirmed using another solvent system, hexane: diethyl ether: acetic acid (65: 35: 0.1, $v / v / v)$. Both developing systems were modified from our previous method [7]. After drying, the developed TLC plates were stained with iodine vapor and then $R_{f}$ values of the identifying spots were calculated.

For testosterone detection, a testosterone standard was dissolved in methanol to obtain $1 \mathrm{mg} / \mathrm{ml}$ solution. A mobile phase was hexane: ethyl acetate: acetic acid (60: 40: 0.5, $v / v / v)$. The developed TLC plate was observed under UV light at $254 \mathrm{~nm}$ (Camag UV cabinet, USA).

2.4. Compound Characterization. The characterization of the phytochemical constituents of the three extracts was performed using Fourier-transform infrared spectroscopy (FTIR) and Proton nuclear magnetic resonance spectroscopy $\left({ }^{1} \mathrm{H} \mathrm{NMR}\right)$. Each extract (approximately $5 \mathrm{mg}$ ) was blended with dried potassium bromide $(100 \mathrm{mg})$ and then compressed to form a pellet using a hydraulic press. The FTIR spectra of extracts were recorded in the mid-infrared region from 4000 to $400 \mathrm{~cm}^{-1}$ using an FTIR spectrometer (Thermo Electron Scientific Instruments Corporation, Madison, WI, USA).

Approximately $10 \mathrm{mg}$ of $\mathrm{HE}, \mathrm{EE}$, and WE were dissolved separately in $4 \mathrm{~mL}$ of chloroform-d, methanol- $\mathrm{d}_{4}$, and dimethyl sulfoxide- $\mathrm{d}_{6}$, respectively, with an internal standard (tetramethylsilane, TMS) and then transferred into $5 \mathrm{~mm}$ NMR tubes. The ${ }^{1} \mathrm{H}$ NMR spectra were recorded with a Bruker AVANCE 400 NMR spectrometer at $400 \mathrm{MHz}$ (Bruker BioSpin GmbH, Rheinstetten, Germany).

\subsection{Analysis of Testosterone Using High-Performance Liquid Chromatography (HPLC)}

2.5.1. Standard and Sample Solutions. The standard stock solution of testosterone was prepared in mobile phase $(0.1 \%$ $v / v$ formic acid: methanol, 10: 90, $v / v)$ and then diluted quantitatively with the same solvent to yield 0.4, 1.2, 1.7, 2.4, 
3.4, 4.9, and $7.0 \mu \mathrm{g} / \mathrm{mL}$. Each freeze-dried extract was dissolved individually in mobile phase and then sonicated for $15 \mathrm{~min}$ at room temperature. The sample solutions were prepared by diluting the extract stock solutions in mobile phase to a concentration of $1 \mathrm{mg} / \mathrm{mL}$.

2.5.2. Chromatographic Condition. HPLC analyses were carried out using an isocratic elution as previously described [8] after suitable modifications. HPLC was performed with an Agilent 1100 Series equipped with an Agilent G1315B diode array detector covering the range $200-800 \mathrm{~nm}$ and interfaced to a computer for data acquisition and a recorder model ChemStation for LC-3D, CE system. The column was a porous spherical silica ReproSil-Pur Basic C18 (250$\mathrm{mm} \times 4.6-\mathrm{mm}$ i.d., $5 \mu \mathrm{m}$ ) from Dr. Maisch HPLC GmbH (Ammerbuch-Entringen, Germany). The mobile phase composed of $0.1 \% v / v$ formic acid: methanol $(10: 90, v / v)$ was first filtered under vacuum through a $0.45 \mu \mathrm{m}$ nylon membrane and degassed using a vacuum membrane degasser prior to utilization. The elution of testosterone was carried out at $25^{\circ} \mathrm{C}$ at a flow rate of $0.3 \mathrm{~mL} / \mathrm{min}$ and detected at the UV wavelength of $240 \mathrm{~nm}$, which was the wavelength where testosterone showed the maximum absorption. Sample solutions were analyzed in triplicate by HPLC using an injection volume of $20 \mu \mathrm{l}$. A testosterone calibration curve was calculated from chromatograms of authentic standard solutions (triplicates). The retention time for testosterone was $20.5 \mathrm{~min}$.

2.5.3. Quality Control. The validity of the modified method was evaluated in accordance with the guidelines of Association of Official Analytical Chemists [9]. The peak area was plotted against each testosterone concentration. Using linear regression, the slope, $y$-intercept, and linearity of the curve were determined. The precision of the assays was calculated as the percentage of relative standard deviation (\% RSD) of determinations according to the following formula: \% $\mathrm{RSD}=(\mathrm{SD} /$ mean $) \times 100 \%$. Limit of detection $(\mathrm{LOD})$ and limit of quantification (LOQ) based on the standard deviation of response $(\sigma)$ and the slope of calibration curve were calculated according to the following formulas: $\mathrm{LOD}=(3.3 \times \sigma) /$ slope and $\mathrm{LOQ}=(10 \times \sigma) /$ slope, respectively. The spike recovery method was performed to evaluate the accuracy of this method. Three different concentrations of standard testosterone $(0.3,1.0$, and $1.4 \mathrm{mg} / \mathrm{ml})$ were spiked to the extract solutions. The average recoveries were calculated using the following formula: recovery $(\%)=$ [(observed amount-original amount)/spiked amount] $\times$ $100 \%$.

\subsection{Antioxidant Activity Measurements}

2.6.1. DPPH Assay. DPPH radical scavenging assay was performed as in our previous study [10] with slight modifications. For deciding the suitable wavelength, wavelength scans from 400 to $800 \mathrm{~nm}$ were performed for reference and measuring cuvettes. As a result, the wavelength of $540 \mathrm{~nm}$ was selected as the most adequate wavelength for determining all extracts. Aliquots of each extract dilution $(2.0 \mathrm{~mL})$ were added to $2.0 \mathrm{ml}$ of DPPH solution $\left(0.2 \times 10^{-3} \mathrm{~mol} / \mathrm{L}\right)$ in methanol to form the desired solution concentrations. The solutions were mixed thoroughly and incubated in the dark at room temperature for $30 \mathrm{~min}$. The decrease in absorbance of each solution was recorded at $540 \mathrm{~nm}$ using a Hitachi U-2900 UV-Vis Spectrometer (Hitachi High-Technologies Corporation, Tokyo, Japan) against a solvent blank. A standard solution of L-ascorbic acid at concentrations between 3 and $40 \mu \mathrm{g} / \mathrm{mL}$ in methanol was employed as a positive control. The radical scavenging activities were expressed as the $\mathrm{IC}_{50}$ values. All experiments were performed in triplicate.

2.6.2. FRAP Assay. Ferric reducing antioxidant power (FRAP) assay was performed based upon our previously reported method [10] with some modifications. The FRAP reagent consists of $0.3 \mathrm{~mol} / \mathrm{L}$ acetate buffer ( $\mathrm{pH} 3.6), 0.1 \mathrm{~mol} /$ L 2,4,6-tris(2-pyridyl)-s-triazine (TPTZ) in $0.4 \mathrm{~mol} / \mathrm{L}$ hydrochloric acid, and $0.2 \mathrm{~mol} / \mathrm{L}$ ferric chloride hexahydrate in distilled water. The FRAP solution $(2 \mathrm{ml})$ was incubated with $10 \mathrm{mg} / \mathrm{mL}$ sample solution $(2 \mathrm{ml})$ in the dark at $37^{\circ} \mathrm{C}$ for $30 \mathrm{~min}$. The absorbance was read at $593 \mathrm{~nm}$ using a Hitachi U-2900 UV-Vis Spectrometer (Hitachi High-Technologies Corporation, Tokyo, Japan) against the reagent blank. Each sample was run in triplicate. L-Ascorbic acid was used as a reference standard and the results were expressed as milligrams of ascorbic acid equivalent per gram of dried extract (mg AAE/g extract).

\subsection{Determination of Essential and Toxic Elements Using} Inductively Coupled Plasma-Mass Spectrometer (ICP-MS). The concentrations of essential elements including $\mathrm{Cu}, \mathrm{Co}$, and $\mathrm{Mg}$ as well as toxic elements such as $\mathrm{As}, \mathrm{Cd}, \mathrm{Hg}$, and $\mathrm{Pb}$ in sample extracts were determined by ICP-MS using microwave digestion as in our previous report [11]. For sample preparation, about $1 \mathrm{~g}$ of extracts was digested separately in triplicate with $7 \mathrm{~mL}$ of $65 \% v / v$ nitric acid solution using a microwave digester Model ETHOS ONE (Milestone Corporation, Sorisole, Italy) until clear solutions were obtained. The digestion solution was diluted to $25.0 \mathrm{ml}$ with ultrapure water and then analyzed by ICP-MS spectrometer, Model 7500ce (Agilent Technologies, Santa Clara, USA). The calibration curves were carried out by external calibration using five different concentrations of an ICP multielement standard solution XIII in 5\% v/v nitric acid solution according to expected concentrations of samples.

2.8. Microbial Limit Test. Microbiological examination in line with the United States Pharmacopeia (USP) 41 [12] was used to determine total aerobic microbial count (TAMC), total yeast, and mold count (TYMC), bile-tolerant gram negative bacteria, Salmonella spp., Escherichia coli, and Staphylococcus aureus in freshly prepared extracts, and those were then kept refrigerated at $4^{\circ} \mathrm{C}$ for 6 months. For determination of TAMC and TYMC using a plate-count 
method, each extract was inoculated in TSA and SDA media and subsequently incubated at $32.5 \pm 2.5^{\circ} \mathrm{C}$ for $3-5$ days and $23.7 \pm 1.0^{\circ} \mathrm{C}$ for $5-7$ days, respectively. After incubation, the colonies that grew on the plates were counted as colony forming units (CFU) per gram of sample. For other bacteria, the plates were incubated aerobically at $32.5 \pm 2.5^{\circ} \mathrm{C}$ for $18-24 \mathrm{~h}$. The samples that did not show growth on the plates were plated on selective agars and then incubated at $32.5 \pm 2.5^{\circ} \mathrm{C}$ for $18-72 \mathrm{~h}$ to observe growth.

2.9. Statistical Analysis. The results were expressed as mean \pm standard deviation (SD). Slopes and intercepts of calibration curves were calculated by linear regression. Correlation coefficient $\left(R^{2}\right)$ values were obtained from MS Office Excel 2010 software. The LODs and LOQs were calculated from the regression data [13]. Student's $t$-test and one-way ANOVA were used to evaluate the significant differences $(p<0.005)$ between the means.

\section{Results and Discussion}

3.1. Yields and Chemical Constituents of Velvet Antler Extracts. HE, EE, and WE of velvet antlers (Figure 1) were obtained through a sequential extraction with hexane, $75 \%$ $v / v$ ethanol, and water, respectively. The percentage yields with respect to dry weight as well as texture and color of $\mathrm{HE}$, EE, and WE are shown in Table 1. WE obtained by digesting the residue from hexane and ethanol extractions in hot water at $45^{\circ} \mathrm{C}$ for $24 \mathrm{~h}$ showed the highest extraction yield while EE prepared by sonicating the residue from hexane extraction in $75 \% v / v$ ethanol at room temperature for $24 \mathrm{~h}$ gave the lowest yield. HE existed in the form of oily semisolid, while $\mathrm{EE}$ and WE appeared as solids at room temperature as shown in Figure 1. The results showed that differences in solvent polarity and extraction conditions influenced the solubility of the chemical constituents in velvet antler powders. Hexane, a nonpolar solvent, will dissolve hydrophobic compounds such as fatty acids and testosterone, while water, a polar solvent, will dissolve some hydrophilic substances such as phenolic compounds and polar antioxidants.

TLC, FTIR, and ${ }^{1} \mathrm{H}$ NMR were used for identification and screening of chemical constituents including oleic acid, linoleic acid, alpha-linolenic acid, and testosterone in all extracts. After staining of the developed plates with iodine vapor, the TLC patterns of $\mathrm{HE}$ and EE revealed the presence of fatty acids including oleic acid, linoleic acid, and alphalinolenic acid at $R_{f}$ values of $0.41,0.40$, and 0.39 , respectively, in the mobile phase system containing hexane: diethyl ether : acetic acid (65:35:0.1, $v / v / v)$. As shown in Figure 2, the developed plates examined under UV light at $254 \mathrm{~nm}$ showed the presence of testosterone at $R_{f}$ values of 0.26 in the lanes of $\mathrm{HE}$ and EE using hexane : ethyl acetate : acetic acid (60: 40: $0.5, v / v / v$ ) as a mobile phase. However, oleic acid, linoleic acid, and alpha-linolenic as well as testosterone were not detected in the WE.

Oleic acid (cis-9 C18:1), as well as linoleic acid $(18: 2$ $n-6)$ and alpha-linolenic acid (C18:3n-3), was classified as monounsaturated and polyunsaturated fatty acids, respectively. The FTIR spectra of $\mathrm{HE}$ and EE exhibited the main absorption bands corresponding to $=\mathrm{C}-\mathrm{H}$ stretching of the carbon-carbon double bonds $\left(3004,2924 \mathrm{~cm}^{-1}\right),-\mathrm{C}-\mathrm{H}$ stretching of the saturated carbon-carbon bonds (2926, $\left.2855 \mathrm{~cm}^{-1}\right), \mathrm{C}=\mathrm{O}$ stretching of the carbonyl functionalities $\left(1745,1655 \mathrm{~cm}^{-1}\right),-\mathrm{C}-\mathrm{O}-\mathrm{C}$ stretching of the carboxylic acid functionalities $\left(1465,1467 \mathrm{~cm}^{-1}\right)$, and $\mathrm{C}-\mathrm{H}$ out of the plane bending of the saturated carbon-carbon bonds (722, $730 \mathrm{~cm}^{-1}$ ). Consequently, all absorption bands observed in the FTIR spectra of $\mathrm{HE}$ and EE were in consonance with the structures of unsaturated fatty acids [14]. Nevertheless, WE showed no peaks in correspondence with those of fatty acid molecules.

In contrast with a published report [15], the FTIR spectra of $\mathrm{HE}$ and $\mathrm{EE}$ were dominated by the intense peaks of the $\mathrm{O}-\mathrm{H}$ stretching $\left(3466,3421 \mathrm{~cm}^{-1}\right)$, aliphatic $\mathrm{C}-\mathrm{H}$ stretching $\left(2923,2921 \mathrm{~cm}^{-1}\right)$, and $\mathrm{C}=\mathrm{O}$ stretching $\left(1745,1655 \mathrm{~cm}^{-1}\right)$ which were related to the hydroxyl group $\left(3382 \mathrm{~cm}^{-1}\right)$, cyclic ring system $\left(2934 \mathrm{~cm}^{-1}\right)$, and $\alpha, \beta$-unsaturated ketone $\left(1663 \mathrm{~cm}^{-1}\right)$ of testosterone, respectively. Furthermore, the spectra of $\mathrm{HE}$ and $\mathrm{EE}$ also showed $\mathrm{C}-\mathrm{O}$ single bond stretching in the hydroxyl with a medium intensity in the fingerprint region (1116-1084 and $1088-1058 \mathrm{~cm}^{-1}$, respectively) corresponding to the region of testosterone $\left(1077-1034 \mathrm{~cm}^{-1}\right)$ [16]. In the case of the FTIR spectrum of WE, there were no peaks consistent with those of testosterone.

In the ${ }^{1} \mathrm{H}$ NMR spectra of $\mathrm{HE}$ and EE Figure 3, the signals (multiplets) in the region of $0.87-2.37,0.84-2.35 \mathrm{ppm}$, respectively, were attributed to methyl, methylene, and allylic protons of the fatty acid fragments. In line with Tociu, Todasca, Bratu, Mihalache, and Manolache [17], both spectra also showed signals (two multiplets) in the range of 4.00-4.32 ppm were regarded as the methylene protons close to the $\mathrm{COOH}$ group as well as the signals (broad multiplets) in the range of 5.24-5.40 and 5.30-5.35 ppm which were assigned to the vinylic $(=\mathrm{CH})$ protons of the double bonds of the fatty acid chains. Testosterone in the ${ }^{1} \mathrm{H}$ NMR spectra of HE and EE exhibited the signals at $0.69-0.99,0.70-0.85 \mathrm{ppm}$ (methyl groups), 3.72, $3.68 \mathrm{ppm}$ (17 $\alpha-\mathrm{CH}$ close to the hydroxyl group), and $5.25-5.40,5.30-5.37 \mathrm{ppm}$ (vinylic methine protons) conforming to a previous report [18]. However, due to the overlapping peaks in ${ }^{1} \mathrm{H}$ NMR spectrum of WE, it is difficult to identify the components relying solely on ${ }^{1} \mathrm{H}$ NMR spectrum.

Velvet antlers from elk (Cervus elaphus canadensis) were composed of fatty acids [19] and those from sika deer (Cervus nippon) and red deer (Cervus elaphus) consisted of testosterone [20]. In this study, oleic acid, linoleic acid, alpha-linolenic acid, and testosterone in rusa deer velvet antlers were extracted and reextracted by increasing polarity from hexane to $75 \% v / v$ ethanol. This finding is in accordance with previous reports $[19,20]$. Moreover, the fingerprints obtained from TLC, FTIR, and ${ }^{1} \mathrm{H}$ NMR had potential to determine authenticity of rusa velvet antlers.

3.2. Determination of Testosterone in Velvet Antler Extracts. The mobile phase containing $0.1 \% v / v$ formic acid : methanol $(10: 90, v / v)$ was used to separate the testosterone in velvet 


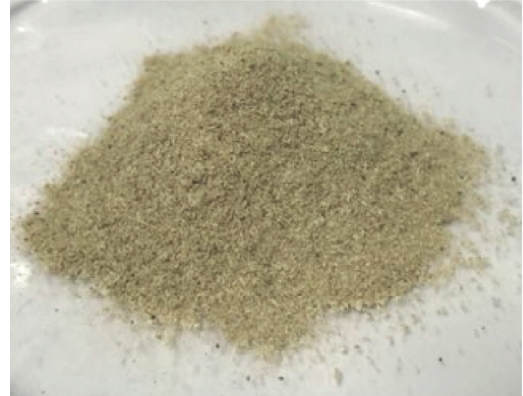

(a)

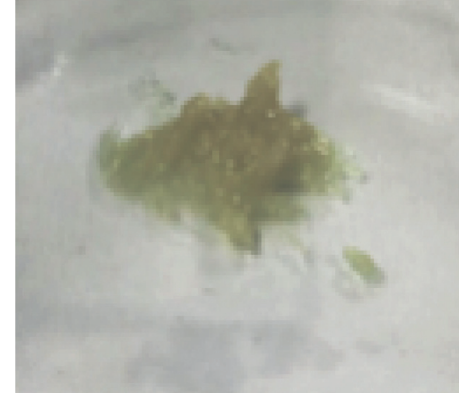

(b)

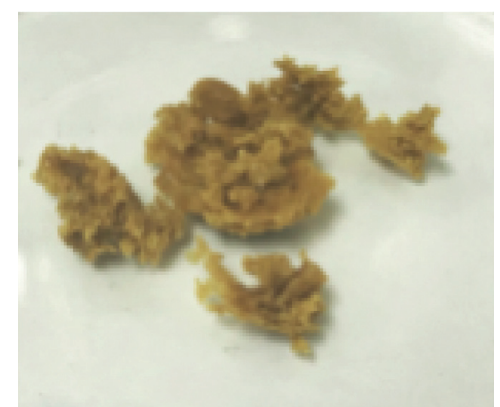

(c)

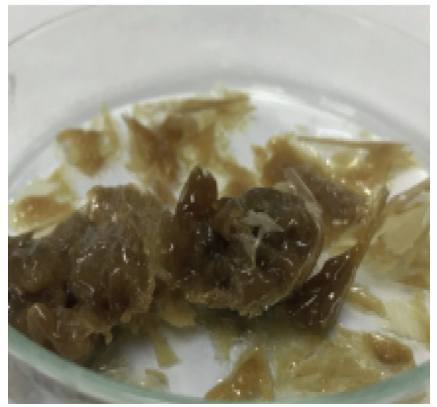

(d)

FIGURE 1: Velvet antler powder (a) was extracted with a three-solvent sequential extraction process to obtain hexane (b), $75 \% v / v$ ethanol (c), and water (d) extracts (HE, EE, and WE, respectively).

TABLE 1: Color, texture, percentage yields, testosterone concentrations, antioxidant activities, and essential and toxic element concentrations of velvet antler extracts.

\begin{tabular}{|c|c|c|c|}
\hline Parameters & Hexane extract (HE) & $75 \% v / v$ ethanol extract (EE) & Water extract (WE) \\
\hline Color & Pale yellow & Yellow & Brown \\
\hline Texture & Semisolid & Solid & Solid \\
\hline Yield (\%) & 1.03 & 0.68 & 5.20 \\
\hline Testosterone concentration $(\mu \mathrm{g} / \mathrm{g})$ & $6.37 \pm 0.01^{\mathrm{a}}$ & $7.46 \pm 0.03^{\mathrm{b}}$ & ND \\
\hline \multicolumn{4}{|l|}{ Antioxidant activities } \\
\hline DPPH IC ${ }_{50}(\mathrm{mg} / \mathrm{mL})$ & $>15.01 \pm 0.01^{\mathrm{c}}$ & $3.48 \pm 0.24^{\mathrm{a}}$ & $6.99 \pm 0.64^{\mathrm{b}}$ \\
\hline FRAP reducing power values (mg AAE/g extract) & NA & $1.52 \pm 0.25^{\mathrm{b}}$ & $0.72 \pm 0.03^{\mathrm{a}}$ \\
\hline \multicolumn{4}{|l|}{ Essential element concentration $(\mathrm{mg} / \mathrm{kg})$} \\
\hline $\mathrm{Cu}$ & $0.210 \pm 0.035$ & $3.111 \pm 0.034$ & $2.735 \pm 0.073$ \\
\hline Co & $0.010 \pm 0.002$ & $319.340 \pm 0.008$ & $0.028 \pm 0.015$ \\
\hline $\mathrm{Mg}$ & $24.700 \pm 10.711$ & $0.031 \pm 0.059$ & $338.068 \pm 15.862$ \\
\hline \multicolumn{4}{|l|}{ Toxic element concentration $(\mathrm{mg} / \mathrm{kg})$} \\
\hline As & $0.150 \pm 0.080$ & $0.390 \pm 0.042$ & $0.375 \pm 0.012$ \\
\hline $\mathrm{Cd}$ & $0.010 \pm 0.001$ & $0.145 \pm 0.005$ & $0.014 \pm 0.010$ \\
\hline $\mathrm{Hg}$ & ND & ND & $0.004 \pm 0.010$ \\
\hline $\mathrm{Pb}$ & $0.070 \pm 0.035$ & $1.485 \pm 0.032$ & $0.273 \pm 0.072$ \\
\hline
\end{tabular}

Each value is represented as mean $\pm \mathrm{SD}(n=3)$. Extraction yield is expressed as $\%$ ( $\mathrm{g}$ extract $/ 100 \mathrm{~g}$ dry velvet antler). Testosterone concentration is calculated as $\mu \mathrm{g} / \mathrm{g}$ dry velvet antler. ${ }^{*} \mathrm{IC}_{50}$ : the inhibitory concentration of the extract needed to inhibit $50 \%$ of the DPPH radicals; reducing property: milligram of ascorbic acid equivalent per gram of an extract (mg AAE/g extract); NA: no activity at the tested concentration; ND: not determined. ${ }^{\mathrm{a}, \mathrm{b}, \mathrm{c}}$ Values in the same row with different superscript letters differ significantly $(p<0.05)$.

antler extracts using a spherical silica ReproSil-Pur Basic column as the stationary phase. Based on this separation, the repeatability as \% RSD for six different standard samples $(0.5-3.4 \mu \mathrm{g} / \mathrm{mL})$ was estimated using peak areas, retention times, and tailing factors $(\leq 2)$. From the results, those RSD values were lower than $1 \%$. The number of theoretical plates was always $\geq 13157$ and the peak of testosterone was well separated (resolution $\geq 2.01$ ) in all chromatographic runs to ensure good efficacy of the column and the robustness of the analytical method throughout the HPLC separation. The calibration curve (7 different concentrations) established for testosterone exhibited good linearity $\left(R^{2}=0.9993\right)$ and the linear regression equation of testosterone was $Y=75.1260$ $X+5.3901$. The calculated LOD and LOQ were 0.13 and 


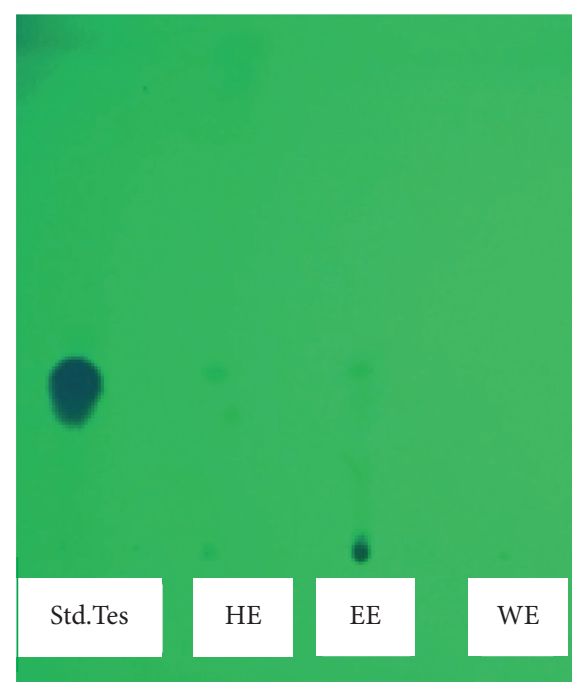

FIgURE 2: TLC patterns of testosterone standard (Std. Tes), hexane extract (HE), 75\% $v / v$ ethanol extract (EE), and water extract (WE) observed under UV light at $254 \mathrm{~nm}$ using hexane: ethyl acetate: acetic acid (60: 40: 0.5, $v / v / v)$ as a mobile phase.

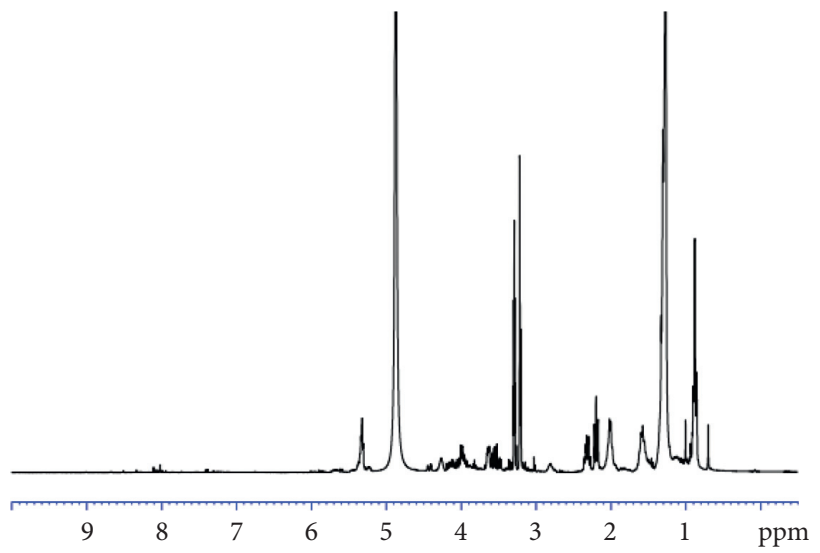

FIgURE 3: ${ }^{1} \mathrm{H}$ NMR spectrum of $75 \% v / v$ ethanol extract (EE) was recorded with a Bruker AVANCE 400 NMR spectrometer at $400 \mathrm{MHz}$.

$0.39 \mu \mathrm{g} / \mathrm{mL}$, respectively. Accuracy was assessed at three different concentration levels of testosterone by triplicate measurements. The modified HPLC-UV analytical method exhibited good accuracy with satisfactory recoveries from $98.65 \%$ to $106.70 \%$ with $\mathrm{RSD}<3.88 \%$. Consequently, the validation parameters obtained using a HPLC-UV were adequate for the determination of testosterone in velvet antler extracts.

This method was applied for the determination of testosterone in velvet antler extracts. The chromatogram of the EE sample is shown in Figure 4. Testosterone was detectable in $\mathrm{HE}$ and $\mathrm{EE}$ samples at concentrations of $6.37 \pm 0.01$ and $7.46 \pm 0.03 \mu \mathrm{g} / \mathrm{g}$ on a dry weight basis, respectively, as shown in Table 1. Nevertheless, testosterone was not quantifiable in the WE sample. A previous study showed that velvet antler extracts are obtained from sika deer and red deer using ultrasonic extraction with methanol and then washed with

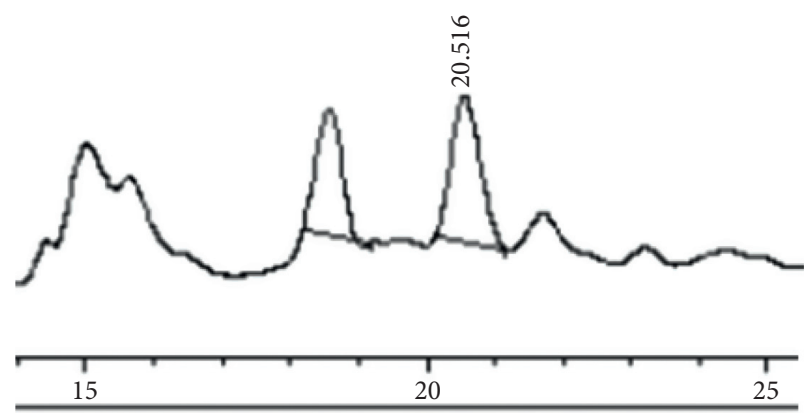

FIgURE 4: HPLC chromatogram obtained from 75\% $v / v$ ethanol extract (EE) using a mobile phase of $0.1 \% v / v$ formic acid : methanol $(10: 90, v / v)$. Conditions: UV-absorbance detection at $240 \mathrm{~nm}$, flow rate $0.3 \mathrm{ml} / \mathrm{min}$ and ReproSil-Pur ODS $(250 \mathrm{~mm} \times 4.6 \mathrm{~mm}$ i.d., $5 \mu \mathrm{m})$ column $\left(25^{\circ} \mathrm{C}\right)$.

hexane contained lower concentrations of testosterone in the range between $0.2 \times 10^{-3}$ and $1.2 \times 10^{-3} \mu \mathrm{g} / \mathrm{g}$ on a dry weight basis ( $\mathrm{Lu}$ et al., [20]). The results of this investigation revealed that testosterone might exist in most velvet antlers and the concentrations of testosterone in velvet antlers of rusa deer might be higher than those of sika deer and red deer.

3.3. Antioxidant Activities of Velvet Antler Extracts. EE and WE demonstrated antioxidant activities with $\mathrm{IC}_{50}$ values of $3.48 \pm 0.24$ and $6.99 \pm 0.64 \mathrm{mg} / \mathrm{mL}$ in DPPH assays and reducing power values of $1.52 \pm 0.25$ and $0.72 \pm 0.03 \mathrm{mg} \mathrm{AAE} / \mathrm{g}$ extract in FRAP assays, respectively. L-ascorbic acid exhibited strong antioxidant DPPH radical scavenging activity with $\mathrm{IC}_{50}$ value of $16.80 \pm 0.09 \mu \mathrm{g} / \mathrm{mL}$. Finally, the EE was more effective in inhibiting DPPH free radical formation and reducing $\mathrm{Fe}^{3+}$ ions than WE, while $\mathrm{HE}$ showed almost negligible activity as shown in Table 1 .

Although the antioxidant activities of several extracts from velvet antlers have been studied, these properties have not been completely explored in rusa velvet antler extracts. As understood on the literature, the $75 \% v / v$ ethanol and water extracts of velvet antlers from sika deer and red deer display antioxidant activities [21, 22]. However, it was not possible to compare the results of antioxidant activities between the present study and previous studies because of different antioxidant units. Further study is necessary for the comparison of antioxidant potentials of velvet antler extracts from various species of deer.

3.4. Heavy Metal Concentrations in Velvet Antler Extracts. The concentrations of essential elements $(\mathrm{Cu}, \mathrm{Co}$, and $\mathrm{Mg})$ and toxic heavy metals ( $\mathrm{As}, \mathrm{Cd}, \mathrm{Hg}$, and $\mathrm{Pb}$ ) in $\mathrm{HE}, \mathrm{EE}$, and WE were determined by ICP-MS. The ICP-MS calibration curves were excellent with good linearity $\left(R^{2}>0.9952\right)$. As shown in Table 1, most sample extracts had high concentrations of essential elements along with low concentrations of toxic heavy metals. The highest concentration of $\mathrm{Cu}$ $(3.111 \pm 0.034 \mathrm{mg} / \mathrm{kg})$ found in the EE was higher than those found in the previous report $(2.64 \pm 71.25 \mathrm{mg} / \mathrm{kg})$ [23]. Furthermore, EE and WE exhibited the highest 
concentrations of Co $(319.340 \pm 0.008 \mathrm{mg} / \mathrm{kg})$ and $\mathrm{Mg}$ $(338.068 \pm 15.862 \mathrm{mg} / \mathrm{kg})$, respectively. The levels of As, Cd, $\mathrm{Hg}$, and $\mathrm{Pb}$ in all sample extracts were below the permissible limits as established by ASEAN guidelines on limits of contaminants for traditional medicines and health supplements version 1.0 for oral use [24]. The results of this study showed that HE, EE, and WE of rusa deer velvet antlers did not pose a threat to human health and could also be used as sources of elemental nutrients.

3.5. Microbial Contamination in Velvet Antler Extracts. According to ASEAN guidelines on the limits of contaminants for traditional medicines and health supplements version 1.0 for oral use [24], the acceptable criteria for extracts from animal origin, based upon TAMC and TYMC, is not more than $2 \times 10^{4}$ and $2 \times 10^{2} \mathrm{CFU} / \mathrm{g}$, respectively. In addition, the number of bile-tolerant gram negative bacteria must not be more than $2 \times 10^{2} \mathrm{CFU} / \mathrm{g}$. Furthermore, none of the specified pathogens including Salmonella spp., Escherichia coli, and Staphylococcus aureus can be observed in $1 \mathrm{~g}$ of sample. The results obtained in the present study showed that all freshly prepared extracts and those kept refrigerated at $4^{\circ} \mathrm{C}$ for 6 months conformed to the required criteria. Therefore, the microbiological quality of all the samples was of a high standard.

\section{Conclusion}

As an innovative methodology, the sequential extraction of rusa velvet antlers with different solvents ranging from nonpolar to polar provided an efficient method for extracting fatty acids, testosterone, and antioxidants. The HE, EE, and WE were evaluated by DPPH and FRAP assays and the EE exhibited the strongest antioxidant activity. The $\mathrm{EE}$ also had the highest concentration of testosterone. HE contained a lower concentration of testosterone than EE and had no antioxidant activity at the highest tested concentration. WE illustrated a weaker antioxidant activity than EE and had no detectable testosterone. Therefore, $75 \% \mathrm{v} / \mathrm{v}$ ethanol is recommended for the extraction of testosterone and antioxidants. Moreover, hexane and water might be suitable for extracting testosterone and antioxidants from rusa deer velvet antlers, respectively. Microbial contamination and toxic heavy metal contents in all extracts were lower than permissible limits set out by ASEAN guidelines. Consequently, it can be concluded that $75 \% v / v$ ethanol extract of rusa deer velvet antlers can be used as a safe source of natural antioxidants and testosterone.

\section{Data Availability}

The data employed to support the findings of this study are contained in the article. The other data are available from the corresponding author upon request.

\section{Conflicts of Interest}

All researchers state that there are no conflicts of interest.

\section{Acknowledgments}

This research was supported by, Faculty of Pharmacy, Silpakorn University, Nakhon Pathom, Thailand (grant no. RAF 006/2564).

\section{References}

[1] C. Sirikhant, "A financial analysis of Rusa deer farming investment in Thailand," http://www.thaithesis.org/detail.php? $\mathrm{id}=\% 201162546001087$, M.S. thesis, Kasetsart University, Bangkok, Thailand, 2003, http://www.thaithesis.org/detail. php?id=\%201162546001087, M.S. thesis.

[2] C.-T. Kim, N. Gujral, A. Ganguly, J.-W. Suh, and H. H. Sunwoo, "Chondroitin sulphate extracted from antler cartilage using high hydrostatic pressure and enzymatic hydrolysis," Biotechnology Reports, vol. 4, pp. 14-20, 2014.

[3] C. Lu, M. Wang, J. Mu, D. Han, Y. Bai, and H. Zhang, "Simultaneous determination of eighteen steroid hormones in antler velvet by gas chromatography-tandem mass spectrometry," Food Chemistry, vol. 141, no. 3, pp. 1796-1806, 2013.

[4] F. Wu, H. Li, L. Jin et al., "Deer antler base as a traditional Chinese medicine: a review of its traditional uses, chemistry and pharmacology," Journal of Ethnopharmacology, vol. 145, no. 2, pp. 403-415, 2013.

[5] N. N. Azwanida, "A review on the extraction methods use in medicinal plants, principle, strength and limitation," $M e$ dicinal and Aromatic Plants, vol. 4, no. 3, 2015.

[6] J. C. Touchstone, "Thin-layer chromatographic procedures for lipid separation," Journal of Chromatography B: Biomedical Sciences and Applications, vol. 671, no. 1-2, pp. 169-195, 1995.

[7] S. Pengon, J. Ponphaiboon, A. Chaidedgumjorn, C. Limmatvapirat, P. Sriamornsak, and S. Limmatvapirat, "Comparison of solvent miscibility of coconut oil and its modified forms," Advanced Materials Research, vol. 1060, pp. 151-154, 2014.

[8] R. Gonzalo-Lumbreras, D. Pimentel-Trapero, and R. Izquierdo-Hornillos, "Development and method validation for testosterone and epitestosterone in human urine samples by liquid chromatography applications," Journal of Chromatographic Science, vol. 41, no. 5, pp. 261-266, 2003.

[9] ICH Harmonized Tripartite Guideline, Validation of Analytical Procedures: Text and Methodology, Q2 (R1), ICH, Geneva, Switzerland, 2005, https://www.ich.org/fileadmin/ Public_Web_Site/ICH_Products/Guidelines/Quality/Q2_R1/ Step4/Q2_R1_Guideline.pdf.

[10] W. Krongrawa, S. Limmatvapirat, N. Pongnimitprasert, P. Meetam, and C. Limmatvapirat, "Formulation and evaluation of gels containing coconut kernel extract for topical application," Asian Journal of Pharmaceutical Sciences, vol. 13, no. 5, pp. 415-424, 2018.

[11] C. Limmatvapirat, S. Limmatvapirat, J. Charoenteeraboon et al., "Comparison of eleven heavy metals in Moringa oleifera Lam. Products," Indian Journal of Pharmaceutical Sciences, vol. 77, no. 4, pp. 485-490, 2015.

[12] The United States Pharmacopeial Convention, " $<61>\mathrm{mi}$ crobiological examination of nonsterile products: microbial enumeration tests," in The United States Pharmacopeia, 41st rev., and the National Formulary, The United States Pharmacopeial Convention, Rockville, MD, USA, 36th edition, 2018.

[13] J. N. Miller and J. C. Miller, Statistics and Chemometrics for Analytical Chemistry, A. Gosport, Ed., Colour Press Ltd., Wembley, England, 6th edition, 2010. 
[14] T. Gocen, S. H. Bayarı, and M. H. Guven, "Effects of chemical structures of omega- 6 fatty acids on the molecular parameters and quantum chemical descriptors," Journal of Molecular Structure, vol. 1174, pp. 142-150, 2018.

[15] J. P. Quinones, J. Jokinen, S. Keinänen, C. P. Covas, O. Brüggemann, and D. Ossipov, "Self-assembled hyaluronic acid-testosterone nanocarriers for delivery of anticancer drugs," European Polymer Journal, vol. 99, pp. 384-393, 2018.

[16] H. L. J. Makin and D. B. Gower, Steroid Analysis, Springer, Dordrecht, Netherlands, 2nd edition, 2010.

[17] M. Tociu, M.-C. Todasca, A. Bratu, M. Mihalache, and F. Manolache, "Fast approach for fatty acid profiling of dairy products fats using $1 \mathrm{H}-\mathrm{NMR}$ spectroscopy," International Dairy Journal, vol. 83, pp. 52-57, 2018.

[18] K. Hayamizu, O. Kamo, and M. Yanagisawa, "Complete assignments of the1H and 13C NMR spectra of testosterone and $17 \alpha$-methyltestosterone and the $1 \mathrm{H}$ parameters obtained from $600 \mathrm{MHz}$ spectra," Magnetic Resonance in Chemistry, vol. 28, no. 3, pp. 250-256, 1990.

[19] B. T. Jeon, S. H. Cheong, D. H. Kim et al., "Effect of antler development stage on the chemical composition of velvet antler in elk (Cervus elaphus canadensis)," Asian-Australasian Journal of Animal Sciences, vol. 24, no. 9, pp. 1303-1313, 2011.

[20] C. M. Lu, M. T. Wang, J. Mu et al., "Determination of sex hormones in antler velvet by high performance liquid chromatography tandem mass spectrometry," Chemical Research in Chinese Universities, vol. 28, pp. 191-194, 2012.

[21] L. Zhao, R.-S. Pei, B.-P. Ji et al., "Antioxidant activity of aqueous extract fractions of velvet antler (Cervus elaphus Linnaeus)," Journal of Food and Drug Analysis, vol. 18, no. 5, pp. 319-327, 2010.

[22] R. Zhou and S. Li, "In vitro antioxidant analysis and characterisation of antler velvet extract," Food Chemistry, vol. 114, no. 4, pp. 1321-1327, 2009.

[23] S.-H. Tseng, C.-H. Sung, L.-G. Chen et al., "Comparison of chemical compositions and osteoprotective effects of different sections of velvet antler," Journal of Ethnopharmacology, vol. 151, no. 1, pp. 352-360, 2014.

[24] The 24th ASEAN Traditional Medicines and Health Supplements Scientific Committee Meeting (ATSC), Association of South East Asian Nations (ASEAN) Guidelines on Limits of Contaminants for Traditional Medicines and Health Supplements, Association of Southeast Asian Nations (ASEAN), Jakarta, Indonesia, 2015, https://www.hsa.gov.sg/content/ dam/HSA/HPRG/Complementary_Health_Products/Annexes/ ANNEX\%20III\%20ASEAN\%20GL\%20on\%20Limits\%20of\% 20Contaminations\%20TMHS\%20V1.0(13Nov14).pdf. 